\title{
The identification of city development types: a case study in central Taiwan
}

\author{
M. S. Cheng \& H. P. Lin \\ Department of Urban Planning, National Cheng Kung University, \\ Taiwan
}

\begin{abstract}
Urban development is a long-term dynamic process in which arises the debate about the causal relationship of population growth and land development. That is, does population growth bring pressure on cities to plan new land developments, or land development cause population to increase? This study does an empirical research in one city and four counties in central Taiwan and sheds some lights on that debate. When cities review their city plans, they face an important decision about whether to permit new land developments. Hence the city plan review offers a natural experiment to test the debate. This study built a model of two simultaneous equations. The two dependent variables are population size and land development area. The sample consists of 113 city plan reviews. The model is run with the two-stage-least-squares method. The result shows that land development is the cause and population growth is the effect. This suggests that cities providing land for development can see their population increase. However, this in turn may be due to the existence of strict national land use control that depicts the location for development.
\end{abstract}

Keywords: population growth, land development, simultaneous equations, city plan.

\section{Introduction}

City development is the process of mutual influences between supply (land development) and demand (population growth). Hirschman [1] pointed out that economic development is a series of processes of unbalanced development. Past unbalanced development will bring out new unbalanced cause-effect elements and drive the economy forward. A development policy should keep the economy 
in a state of strain and imbalance. Similarly, city development is a long-term dynamic process in which population growth and land development may occur in different stages. It is rare to have the two aspects kept in balance in the same stage.

The work of policy planning is to develop a plan, method, and strategy that will tackle problems and serve needs. To fulfil policy, an action strategy should be developed to deal with public issues. With respect to city planning, the choice of city development strategy is a policy planning process. Local governments should refer to upper-level plans (e.g., regional plans, county comprehensive development plans), policy guidance (e.g., industry development policy), existing local development, and future development targets to formulate a city development strategy.

In urban planning, the development of commercial and industrial areas in planned districts attracts the employment-seeking population and merchants. Studies performed by [2-5] showed that the number of persons employed in and employment growth rates of secondary and tertiary industries significantly affect regional population migration.

As both a cause and a consequence of social change, human migration is regarded as the key factor underlying the demographic and socioeconomic composition of regions. Thus, for anyone attempting to analyze the general process of regional change, an understanding of interregional migration is vital. Accordingly, policy makers have become increasingly aware of the role of migration in the context of such socioeconomic issues as regional growth, social well-being, and political representation [6]. Miller [7] believes that to make good decisions, decision-makers must be aware of the relationship between changing patterns of interstate migration and changes in regional and national economic growth as well as spatial patterns of economic activity. The growth of states and regions relates closely to population growth, which is mostly a result of migration.

Thus, it seems plausible that any study of migration flow would make it possible (1) to better understand the growth of regions, the factors causing this growth, and the interrelationship of these factors; (2) to more accurately anticipate and prepare for future growth in different regions (especially growth that might cause problems or create new opportunities in many sectors of the economy); and (3) to study policies that could increase (or induce) growth [2].

Accurately modelling the local economic and fiscal impacts of employment growth requires knowledge of who actually gets those new jobs. Early fiscal impact models tended to assume, often implicitly, that local labour markets clear internally, in the sense that new jobs a firm or industry brings to a community are taken entirely by current residents of the community [8].

Studies by [5, 9-14] showed that higher wages attract correspondingly larger amounts of population immigration and create regional population growth. When considerable population migration occurs, the population residing in the planning area will increase.

To discover the causal relationship between population growth and land development, this study draws a sample of local jurisdictions in one city and four 
counties of central Taiwan, fig. 1, and builds a model of two simultaneous regression equations. The dependent variables are existing population and land use area in each jurisdiction. Periodical reviews of city plans, focusing on population and land use area, are typically carried out. This study applied modelling to a real world situation. Data for variables in the model reflect the real world situation, i.e., they are not the forecasts of population and land use area that are usually seen in planning documents. Two-stages-least-squares estimation is used to estimate the relevant parameters of the model and test its reliability.

The paper is organized in five sections. Section 1 is this introduction, and section 2 deals with model building and the rules of causality testing. Section 3 gives definitions for the variables in the model. Section 4 explains the empirical results, while section 5 discusses the study and presents concluding remarks.

\section{The model and rules for causality testing}

\subsection{City development types}

There are two types of city development can be distinguished. Type 1 development refers to the case that population growth is the cause and land

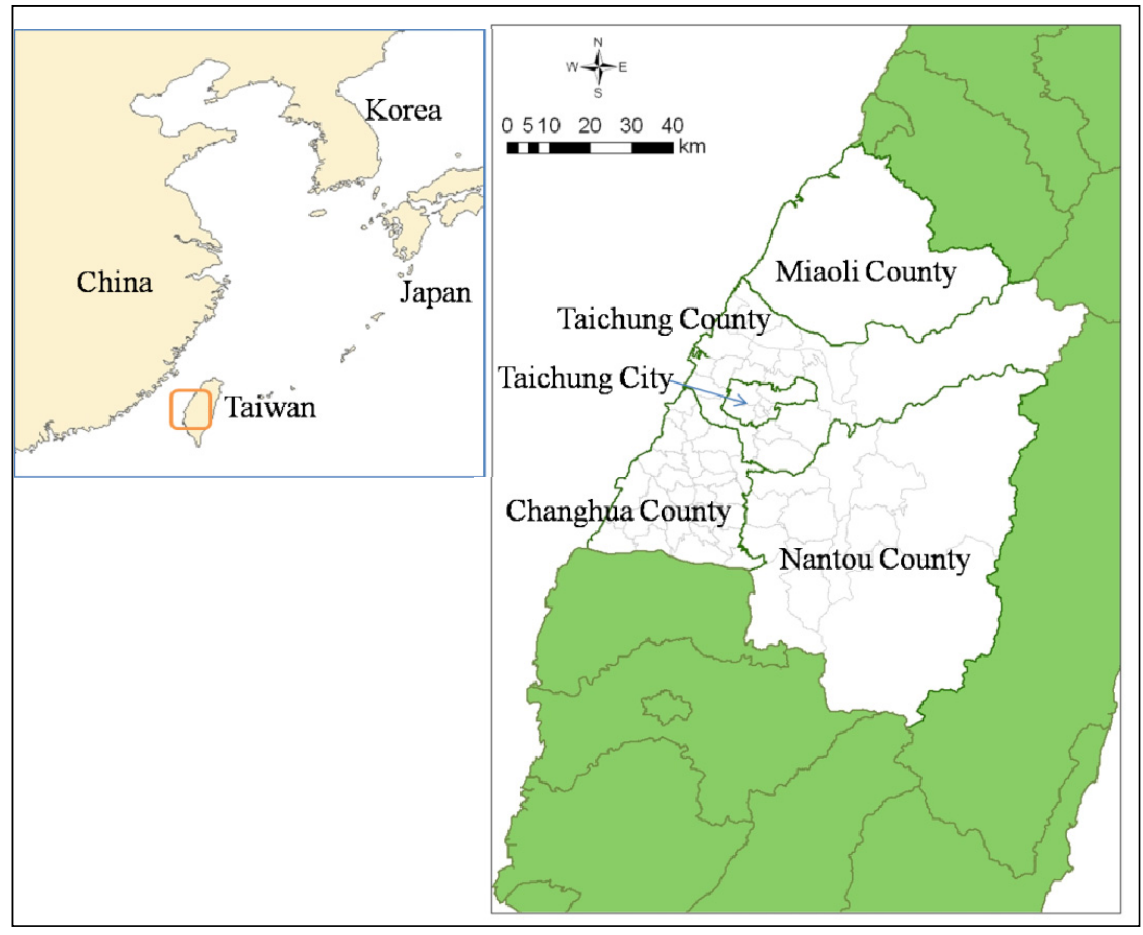

Figure 1: The case study region. 
development is the effect. That is, population gain of a city induces land development to follow. Development of this type has the advantage that investment in land development is not going to fail easily, the risk of land development is reduced and the financial burden on local government is decreased. However, when population increases rapidly and the city is unable to finance land development, pressure of population growth over a city's carrying capacity would cause problems such as that infrastructure is inadequate, traffic is congested, and residential quality deteriorates.

Type 2 development is the case that land development in a city is the cause and population growth is the effect. That is, land development is provided to lure immigration and population growth is realized. The advantage for this type is that local governments can plan land development, land subdivision and infrastructure is completed well in advance to lure further private sector investments and immigrants, and traffic congestion can be ameliorated. Disadvantages may arise if the economy declines sharply and unexpectedly. In that case, population and industry do not enter the developed areas. Subdivision plots and infrastructure are underutilized, and cities will bear a heavy financial burden.

\subsection{The model and the adjustment parameters}

It is assumed that reasonable levels of population $P^{E}$ and land use area $L^{E}$ exist for each jurisdiction. These levels are determined by the equations below. Assume that at the $t^{\text {th }}$ review of the city plan of jurisdiction $i$, the reasonable population level is $P_{i, t}^{E}$, which is related to land use area $L_{i, t}$ and other exogenous variables $Y_{i, t}^{p}$ affecting population growth. As a result, the population equation can be written as follows:

$$
P_{i, t}^{E}=\alpha_{1}^{p} L_{i, t}+\alpha_{2}^{p} Y_{i, t}^{p}
$$

in which superscript $E$ represents the reasonable level, and superscript $p$ represents population; subscript $i$ represents the $i^{\text {th }}$ jurisdiction, where $i=1,2, \ldots, n$; $\alpha_{1}^{p}$ and $\alpha_{2}^{p}$ are coefficients. Since the coefficients are determined by the regression method with a sample of jurisdictions, the reasonable level reflects the common trends of the sample.

Also assume that the reasonable level of land use area is $L_{i, t}^{E}$, which is related to jurisdiction $i$ 's population $P_{i, t}$ and other exogenous variables $Y_{i, t}^{l}$ affecting land use areas. The land area equation can be written as follows:

$$
L_{i, t}^{E}=\alpha_{1}^{l} P_{i, t}+\alpha_{2}^{l} Y_{i, t}^{l}
$$

in which superscript $l$ relates to land; $\alpha_{1}^{l}$ and $\alpha_{2}^{l}$ are coefficients. 
This paper takes population growth as an example to explain the relationship between the most recent overall review and the one preceding it. If the population size is $P_{i, t-1}$ at time $t-1$ (as point $a$ ), fig. 2, and the population size reaches the equilibrium value at time $t$ (as point $f$ ), then, under ideal circumstances, the population size increase that was required to reach the equilibrium value is equal to the difference from the population size in the previous review $\left(P_{i, t}^{E}-P_{i, t-1}\right)$. Population growth is influenced by factors such as local land development, industry, employment opportunities, and environment living conditions. The effect of these factors is influenced by the actual adjustment $(\lambda)$ of the current environment; this coefficient represents the actual reaction to current development in the planning area.

When $\lambda_{p}=1$, the population size $\left(P_{i, t}\right)$ of urban planning area $i$ will equal the reasonable value $\left(P_{i, t}^{E}\right)$ in the $t^{\text {th }}$ review; population growth has attained a reasonable scale, and the adjustment speed is also reasonable. When $\lambda_{p}>1$, the land and supply of other variables impacting population have significant positive reactions, eqn. (1), meaning that the adjustment speed is too fast, causing $P_{i, t}>$ $P_{i, t}^{E}$ (as point $g$ ). When $0<\lambda_{p}<1$, population growth reaction coefficients react positively toward supply, causing $P_{i, t}<P_{i, t}^{E}$, meaning that the adjustment speed is too slow (as point $e$ ). When $\lambda_{p}=0, P_{i, t}$ has not been adjusted and is less than $P_{i, t}^{E}$ (as point $d$ ). When $\lambda_{p}<0$, population growth adjustment coefficients have no response to supply, causing $P_{i, t}<P_{i, t}^{E}$, meaning that the adjustment speed is the slowest (as point $c$ ).

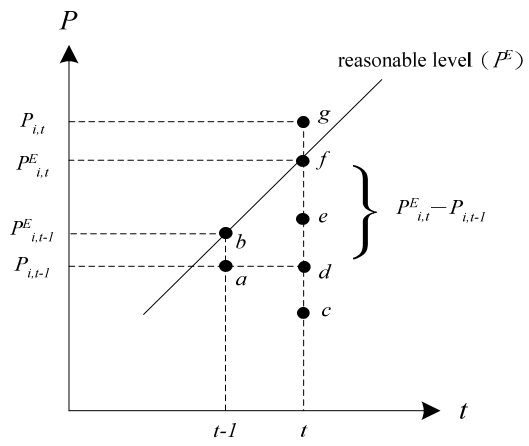

Figure 2: Past and current population growth correlation. 


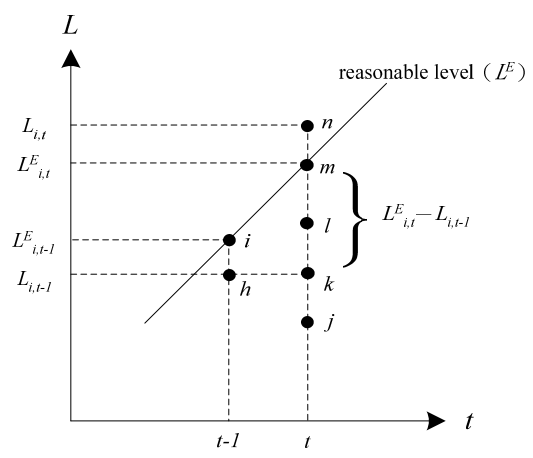

Figure 3: $\quad$ Past and current land use area correlation.

Past and current change relationships relating to land development can be explained in the same way as the change relationships relating to population size described above, fig. 3 .

$$
P_{i, t}=P_{i, t-1}+\lambda_{p}\left(P_{i, t}^{E}-P_{i, t-1}\right)
$$

Similarly, the jurisdiction's reasonable land area $L_{i, t}^{E}$, current land area $L_{i, t-1}$, and adjustment parameter $\lambda_{l}$ determine the land area of the next time period, eqn. (4).

$$
L_{i, t}=L_{i, t-1}+\lambda_{l}\left(L_{i, t}^{E}-L_{i, t-1}\right)
$$

Substituting eqn. (1) in eqn. (3) and eqn. (2) in eqn. (4) yields equations for population and land areas.

$$
\begin{gathered}
P_{i, t}=\lambda_{p} \alpha_{1}^{p} L_{i, t}+\lambda_{p} \alpha_{2}^{p} Y_{i, t}^{p}+\left(1-\lambda_{p}\right) P_{i, t-1} \\
L_{i, t}=\lambda_{l} \alpha_{1}^{l} P_{i, t}+\lambda_{l} \alpha_{2}^{l} Y_{i, t}^{l}+\left(1-\lambda_{l}\right) L_{i, t-1}
\end{gathered}
$$

To estimate eqn. (5) and eqn. (6), we need to include an intercept and an error term in each equation. The complete regression models are eqn. (7) and eqn. (8).

$$
\begin{gathered}
P_{i, t}=\alpha_{0}^{p}+\lambda_{p} \alpha_{1}^{p} L_{i, t}+\lambda_{p} \alpha_{2}^{p} Y_{i, t}^{p}+\left(1-\lambda_{p}\right) P_{i, t-1}+\varepsilon_{i, t}^{p} \\
L_{i, t}=\alpha_{0}^{l}+\lambda_{l} \alpha_{1}^{l} P_{i, t}+\lambda_{l} \alpha_{2}^{l} Y_{i, t}^{l}+\left(1-\lambda_{l}\right) L_{i, t-1}+\varepsilon_{i, t}^{l}
\end{gathered}
$$


$\alpha_{0}^{p}$ and $\alpha_{0}^{l}$ are intercepts, $\varepsilon_{i, t}^{p}$ and $\varepsilon_{i, t}^{l}$ are the error terms, $\varepsilon_{i, t}^{p} \sim N\left(0, \sigma^{2}\right)$, and $\varepsilon_{i, t}^{l} \sim N\left(0, \sigma^{2}\right)$. Both $\varepsilon_{i, t}^{p}$ and $\varepsilon_{i, t}^{l}$ have zero as their means and have the same variance, $\sigma^{2}$.

\subsection{The rules for causality testing}

To perform a causality test, previous researchers chose to compare the parameters of relevant explanatory variables [15-17]. By comparing the parameter $\lambda_{p} \alpha_{1}^{p}$ of $L_{i, t}$ in eqn. (7) with that of $\lambda_{l} \alpha_{1}^{l}$ of $P_{i, t}$ in eqn. (8), the causality of population and land use area can be determined. The rule for the determination is as follows:

\subsubsection{If one of the two parameters is statistically significant and the other is not}

The significant one determines the causality. For example, $\lambda_{p} \alpha_{1}^{p}$ is significant, and $\lambda_{l} \alpha_{1}^{l}$ is not. Then pick eqn. (7) to describe the causality. That is, an increase in land use area is the cause and will bring in an increase of population, which is the effect.

\subsubsection{If both parameters are not significant}

The causality is undetermined.

\subsubsection{If both parameters are significant}

We have three cases for further classification.

(a) If their signs are one positive and one negative, the positive one determines the causality, for the negative one is not conducive to ex ante assessment.

(b) If both have positive signs, the one with the bigger value determines the causality. Or, from another viewpoint, the pair of population and land use area is determined simultaneously [15].

(c) If both have negative signs, the existing theory has to be modified or supplemented.

\section{Definition of variables}

In the study region, we had 113 urban-planning-overall-review (UPOR) cases from 80 urban planning districts in one city and four counties. The sample consists of the 113 cases. For each case we compile the data for the endogenous and exogenous variables. Definitions for those variables are explained below. 


\subsection{Endogenous variables}

We have two endogenous variables. One is the current population size of the jurisdiction in which the UPOR case locate; the other, the current land use area of the UPOR case.

\subsection{Exogenous variables}

\subsubsection{Level of salary}

Level of salary refers to the average salary per worker for a township in which an urban planning district locates. The data comes from trade and industry census of the Executive Yuan Directorate-General of Budget, Accounting, and Statistics. The unit for the variable is NTD (New Taiwan Dollars) 1000 per worker.

\subsubsection{Social increase of population}

Every report of a UPOR case lists, of the jurisdiction, social increase of population that is equivalent to net immigration of population. The unit is number of population.

\subsubsection{Unemployment rates}

The unemployment rate of a township is the number of unemployed persons divided by the number of economically active individuals of at least age 15 . Its unit is $\%$.

\subsubsection{Land prices}

Higher land prices mean higher land development costs. To understand the effect of land prices on land use and development, this study selected the average area land values of the residential, commercial, and industrial areas of each urban planning area as the average area land value for that planning area. The information came from the Department of Land Administration of the Ministry of the Interior; units are in \$NTD/meter ${ }^{2}$.

\subsubsection{Employed workers by secondary and tertiary industries}

This paper examines the relationship between growth trends of employment in secondary and tertiary industries and population growth. The data came from industry and commercial census data from the Executive Yuan DirectorateGeneral of Budget, Accounting, and Statistics; units are individuals.

For this paper, we screened variables through relevant coefficient analysis to select appropriate variables and avoid estimation deviations due to excessive collinearity. Pearson relevant coefficient testing showed that secondary industry employment and tertiary industry employment have significant degrees of correlation (0.883). As a result, this study removed the tertiary industry employment variable and kept only the secondary industry employment variable.

\section{Empirical results}

This study used the SPSS quantitative analysis software to establish a simultaneous equation model and test the parameters and reliability of the model. 
The models of eqn. (7) and eqn. (8) can be used to discuss the causal relationship between population growth and land development. The results of establishing the empirical model are explained as follows.

\subsection{Population growth}

As shown in Table 1, the $\mathrm{R}^{2}$ value of this model after adjustment is 0.985 , indicating excellent explanatory power. Results show that increasing the land use area in an urban planning district by 1 hectare (ha) will produce a population increase of 15.307 people. Opening the total land use area in the urban planning district will stimulate population growth in the district. An increase of 1 person in gross immigration will lead to an increase of 1.786 people in current population in the district. An increase of 1 person in the population of the preceding period leads to an increase of 0.928 people in the current population.

\subsection{Land development}

As shown in Table 2 , the $\mathrm{R}^{2}$ value of this model is 0.883 , indicating excellent explanatory power. Results show that an increase of 1 person in the current population of an urban planning district will lead to a decrease of 0.0004 ha in land use area. This shows that growth in the current population of the planning district will reduce district overall land use area and opening. An increase of 1 person in secondary industry employment will lead to an increase of 0.0003 ha in planning district land use area. Opening an additional 1 ha of land use area in the preceding period increases land use area in the current period by 1.098 ha.

\subsection{Causality test}

Table 1 shows that the parameter of current land development is significant and positive (15.307), and Table 2 shows that the parameter of current population is significant but negative $(-0.0004)$. Based on the rule of causality testing, if their

Table 1: $\quad$ Results, population growth equation.

\begin{tabular}{cc}
\hline Variable & Parameter Estimate(t value) \\
\hline Intercept & $-1129.403(-2.389)^{*}$ \\
Current land development area & $15.307(5.065)^{* *}$ \\
Salary levels & $1.834(1.117)$ \\
Social increase of persons & $1.786(4.492)^{* *}$ \\
Unemployment rates & $41.827(0.295)$ \\
Secondary industry of employed persons & $0.052(1.599)$ \\
Previous population & $0.928(56.312)^{* *}$ \\
\hline Adjusted R $\mathrm{R}^{2}$ & 0.985 \\
Samples & 113 \\
\hline
\end{tabular}

*Indicates significance at the $95 \%$ confidence level.

**Indicates significance at the $99 \%$ confidence level. 
Table 2: $\quad$ Results, land development equation.

\begin{tabular}{cc}
\hline Variable & Parameter Estimate $(\mathrm{t}$ value $)$ \\
\hline Intercept & $0.512(0.117)$ \\
Current population & $0.0004(-1.773)^{*}$ \\
Residential land prices & $0.00005(0.195)$ \\
Commercial land prices & $0.00005(0.413)$ \\
Industrial land prices & $0.00001(0.036)$ \\
Secondary industry of employed persons & $0.0003(1.761)^{*}$ \\
Previous land development area & $1.098(15.960)^{* *}$ \\
\hline Adjusted $\mathrm{R}^{2}$ & 0.883 \\
Samples & 113 \\
\hline *Indicates significance at the 95\% confidence level. \\
**Indicates significance at the 99\% confidence level.
\end{tabular}

signs are one positive and one negative, the positive one determines the causality, for the negative one is not conducive to ex ante assessment. The result illustrated that land development is the cause, and population growth follows where land development occurs.

\section{Discussion and conclusions}

Urban development is a long-term dynamic process in which debate arises about the causal relationship of population growth and land development. That is, does population growth bring pressure on cities to plan new land development, or does land development cause population to increase? This study empirically examined five counties in southern Taiwan and provides data relevant to that debate. When cities review their city plans, they collect many kinds of data. Then they face an important decision about whether to allow new land development. Hence, city plan review offers a natural experiment to test the debate.

This study built a model of two simultaneous equations. The two dependent variables are population size and land area. Embedded in each equation is an adjustment parameter. The population adjustment parameter will measure whether population growth is sensitive to or follows land development. On the other hand, the land development adjustment parameter will measure whether land development is sensitive to or follows population growth. The test sample includes 113 city plan reviews. The model was run with the two-stage-leastsquares method. The result shows that the population reaction parameter is positive, which means that population follows land development, and the land development reaction parameter is negative, which means that a population increase will not always cause new land development. This reflects the fact that having suitable land for development may correlate with population growth in a city, and cities with limited expandable land that are experiencing population growth may cause a migration flow because no new land development is feasible. 
Making regular or contingent reviews of city plans is one of the great tasks of local governments. Typically, city planners have to formulate a development strategy for the land use aspect of the city plan. When city planners try to devise a strategy, they must decide whether to provide a larger space to attract population to move into the city or to wait for population growth to reach a high enough level to expand the land use area. In other words, in terms of population and land use area, the question is which is the cause and which is the effect.

When local governments release annual reports of city plan reviews, the latest data on population and land use area will be on the list. This study takes data from five counties in southern Taiwan to test the causality of population and land use area. A model of two simultaneous equations was built to obtain the parameters of the two relevant variables. Under the rules for determining causality, the result clearly shows that land use area is the cause, and population growth is the effect. How does this fit the reality?

Our explanation is shown below. Major actions to change the city plan by local governments should be submitted to the central government for approval. The proposal to expand city boundaries for new development is a good example. In some cases, land use is not a local affair. It is under tight control by the central government. Proposals for new development should include a feasibility study for reference and offer a clear financial plan. In such a study, the general economic viability and historical trend of population growth for the city are evaluated. It is not surprising that the historical trend of population growth has more weight in obtaining approval from the central government.

In short, development proposals that seem likely to succeed will get passed, and those that seem unlikely to succeed will not. Cities whose development proposals are approved prepare land subdivision, and population rises, while cities without development stay the same. Hence, land use area is the cause, and population is the effect. Land use control predetermines the outcome that is embedded in the system. The model correctly reveals the mechanism of land use control in Taiwan.

\section{References}

[1] Hirschman, A. O., The Strategy of Economic Development, New Haven: Yale University Press, 1958.

[2] Anjomani, A., Regional growth and interstate migration. Socio-Economic Planning Sciences, 36(4), pp.239-265, 2002.

[3] Greenwood, M. J., An econometric model of internal migration and regional economic growth in Mexico. Journal of Regional Science, 18(1), pp.17-31, 1978.

[4] Greenwood, M. J., Hunt, G. L., \& McDowell, J. M., Migration and employment change: empirical evidence on the spatial and temporal dimensions of the linkage. Journal of Regional Science, 26(2), pp.223-234, 1986.

[5] Juarez, J. P., Analysis of interregional labor migration in Spain using gross flows. Journal of Regional Science, 40, pp.337-399, 2000. 
[6] Cadwallader, M., Migration and Residential Mobility: Macro and Micro Approaches, Wisconsin: University of Wisconsin Press, 1992.

[7] Miller Jr. G. H., Dynamic of the US interstate migration system 19751992. Growth and Change, 26, pp.139-160, 1995.

[8] Renkow, M., Employment growth, worker mobility, and rural economic development. American Journal of Agricultural Economics, 85(2), pp.505513, 2003.

[9] Davies, P. S., Michael, J. G., \& Haizheng Li, A conditional logit approach to U.S. state-to-state migration. Journal of Regional Science, 41, pp.337360, 2001.

[10] Harris, J. R. \& Michael, P. T., Migration, unemployment and development: a two-sector analysis. American Economics Review, 60, pp.126-142, 1970.

[11] Jackman, R. \& Savvas, S., Regional migration in Britain: an analysis of gross flows using NHS central register data," The Economic Journal, 102, pp.1433-1450, 1992.

[12] Knapp, T. A., Nancy, E. W., \& David, E. C., A nested logit approach to household mobility. Journal of Regional Science, 41, pp.1-22, 2001.

[13] Molho, I., A dynamic model of interregional migration flows in Great Britain. Journal of Regional Science, 24, pp.317-337, 1984.

[14] Ritsila, J. \& Marko O., Migration and regional centralization of human capital. Applied Economics, 33, pp.317-325, 2001.

[15] Cooke T. W., Causality reconsidered: a note. Journal of Urban Economics, pp.538-542, 1978.

[16] Edmiston, K. D., The net effects of large plant locations and expansions on county employment. Journal of Regional Science, 44(2), pp.289-319, 2004.

[17] Steinnes, D. N. \& Fisher, W. D., An econometric model of intraurban location. Journal of Regional Science, 14(1), pp.65-80, 1974. 